\title{
Excessive Alcohol Intake and Cigarette Smoking among Black Schoolchildren in a Central African City (Brazzaville, Congo)
}

\author{
Annie Rachel Okoko, Gaston Ekouya Bowassa, Bertrand Fikahem Ellenga Mbolla*, \\ Moyen Engoba, Paul Ossou-Nguiet, Suzy-Gisèle Kimbally-Kaky, Georges Marius Moyen \\ Department of Doctoral Studies, Faculty of Health Sciences, Marien Ngouabi University of Brazzaville, Brazzaville, Congo \\ Email: ${ }^{*}$ ellenga_bertrand@hotmail.com
}

How to cite this paper: Okoko, A.R., Bowassa, G.E., Mbolla, B.F.E., Engoba, M., Ossou-Nguiet, P., Kimbally-Kaky, S.-G. and Moyen, G.M. (2017) Excessive Alcohol Intake and Cigarette Smoking among Black Schoolchildren in a Central African City (Brazzaville, Congo). Open Journal of Pediatrics, 7, 18-25.

https://doi.org/10.4236/ojped.2017.71003

Received: December 15, 2016

Accepted: February 10, 2017

Published: February 13, 2017

Copyright $\odot 2017$ by authors and Scientific Research Publishing Inc. This work is licensed under the Creative Commons Attribution International License (CC BY 4.0).

http://creativecommons.org/licenses/by/4.0/

\begin{abstract}
Objective: To determine the prevalence of excessive alcohol intake (EAI) and cigarette smoking (CS) in schoolchildren of Brazzaville. Methods: This cross sectional survey included a representative population of schoolchildren in Brazzaville (603 schoolchildren divided 325 girls and 278 boys). Results: The prevalence of EAI was $9 \%(n=54)$. The mean age of EAI children was $16.2 \pm$ 1.3 years (range: $13-18$ years) vs $11.4 \pm 3.4$ years (range: 5 - 18 years) for no EAI children $(\mathrm{p}<0.001)$. In logistic regression, the independents determinants of EAI were: age, alcoholism in parent, orphans, siblings, low social level. The receiving operative curve (ROC) of age and EAI shown a sensitivity of $74.1 \%$ and specificity of $85.1 \%$ for 15.5 years: area under curve (AUC) $=$ 0.891 (95\% IC: $0.86-0.92 ; \mathrm{p}<0.001)$. The prevalence of CS was $2.5 \%(\mathrm{n}=15)$. The mean age of smokers children was $15.9 \pm 1.5$ years (range: $13-18$ years) vs $11.7 \pm 3.6$ years (range: $5-18$ years) for no smokers children $(\mathrm{p}<0.01)$. In logistic regression, the independents determinants of CS were: siblings, migration, orphans, male sex. The ROC of age and cigarette smoking shown a sensitivity of $73.3 \%$ and specificity of $73.6 \%$ (AUC: 0.839 ; $95 \%$ IC: $0.77-0.90$; $\mathrm{p}=0.035)$ for 14.5 years. Conclusion: Low social level, siblings, addictions in parents were correlate addictions in schoolchildren. It is necessary to prevent the acute and futures complications of this addiction in our children.
\end{abstract}

\section{Keywords}

Smoking, Alcohol, Child, School, Sub-Saharan Africa

\section{Introduction}

Smoking and alcohol addictions are recognized as cardiovascular risk factors [1]. These addictions are becoming an increasingly plagues among children and 
adolescents, exposing them to acute and chronic complications [1] [2] [3].

Worldwide, the school children are also exposed to these addictions. These addictions affect all regions of the world, and are favored by globalization and habits changes [4]. Some social and family factors are also implicated [4] [5] [6]. In sub-Saharan Africa (SSA), these addictions were evaluated mainly in adolescents [7] [8]. Thus, the prevalence of alcoholism in adolescents varies from $16.7 \%$ in Tanzania [9] to $55.5 \%$ in Gabon [7]; and the smoking of $10.6 \%$ in South Africa [6] to 21\% in Gabon [7]. In South Africa, these addictions among adolescents had correlate with crime, cardiovascular diseases, and cancer [1]. In Congo, the law banning smoking in and around schools was adopted, to reduce tobacco-related diseases [10].

In 2005, the prevalence of alcoholism in adolescent was $22.8 \%$ in urban area of Brazzaville [5]. In School area of Brazzaville, any study concern addictions has been conducted.

The aim of this study was to determine the prevalence of excessive alcohol intake (EAI) and cigarette smoking (CS) among schoolchildren in Brazzaville.

\section{Methods}

\subsection{Type, Area and Period of Study}

This cross sectional survey was conducted from March to May 2011 (3 months) in primary and secondary education schools from city of Brazzaville (Republic of Congo). Schools were randomly selected according to their distribution zones (North and South) and exercise (public or private).

\subsection{Subjects}

A representative sample of 603 children and adolescents were included (325 girls, 278 boys). A selection of $1 / 10$ was carried out among 219 schools from the city of Brazzaville at the time of the survey. At the time of the study, this town had three school districts, according to the division made by the Department of Elementary and Secondary Education of Congo. The criteria of inclusion approach were consistent with that of Kimbally-kaky et al. [11]. Thus, the calculated sample size was $600+6(10 \%$ potential missing $)=606$ eligible schoolchildren. A questionnaire was used during the study. The ethical guidelines of the Helsinki protocol were followed, and approval of the Ethics Board of the Faculty of Health Sciences has been obtained.

\subsection{Variables Analyzed}

They were epidemiological: age, sex, educational level, number of siblings, social level, excessive alcohol intake and cigarette smoking, addiction among parents.

\subsection{Definitions}

Migration has been defined by living in Brazzaville for less than 2 years. Adolescence defined by the children of 10 to 18 years old, according to the definition of WHO. Promiscuity was in occupation of a bedroom with 4 or more children. 
Orphans were children who lost both 2 parents, or those who lost a parent, but not living with the living. The high social status was defined by occupation and salary of parents. EAI was define for use at least once a week, and CS by frequent use in the past 30 days [1].

\subsection{Statistical Analysis}

Data were processed using Epi Info 3.3.2 ${ }^{\circledR}$ (CDC Atlanta, USA) and SPSS 16 for Windows ${ }^{\oplus}$. The qualitative variables are presented as numbers and percentages; the quantitative as mean \pm standard déviation (s.d) with range. The independents determinants of EAI and CS were calculated by logistic regression. The receiving operating curve (ROC) were build for evaluation of the area under curve (AUC) to etablish the relationship of age with addictions. The level significance of results was 0.05 .

\section{Results}

Among the schoolchildren, there were 325 girls (53.8\%), 308 adolescents (51\%) and 38 orphans $(6.3 \%)$. The other epidemiological characteristics are reported in Table 1 .

\subsection{Excessive Alcohol Intake}

We noticed 54 schoolchildren (9\%, 95\% CI: 6.9 - 11.6) who admitted to regularly drinking alcohol. There were 26 girls (8\%, 95\% CI: 5.4 - 11.6) and 28 males (10.1\%, 95\% CI: $6.8-14.2)$. The prevalence of EAI according to age range is

Table 1. Distribution of subjects per the epidemiological characteristics. Dichotomous variables are represented in numbers and percentages in parentheses; and quantitative variables as mean \pm standard deviation.

\begin{tabular}{cc}
\hline Female sex & $\mathrm{n}(\%)$ or mean \pm s.d \\
\hline Age & $325(53.8)$ \\
$<8$ years & $11.8 \pm 3.6$ \\
$8-11.9$ years & $120(19.9)$ \\
$12-15.9$ years & $141(23.4)$ \\
$>16$ years & $220(36.5)$ \\
Adolescents & $122(20.2)$ \\
Migration & $308(51)$ \\
Siblings & $67(11)$ \\
Promiscuity & $4 \pm 1.8(1-12)$ \\
Primary school & $275(45.6)$ \\
High school & $315(52.2)$ \\
Private school & $288(47.8)$ \\
Public school & $319(53)$ \\
High social level & $284(47)$ \\
Orphans & $360(60)$ \\
& $38(6.3)$
\end{tabular}


given in Figure 1(a). The distribution of students according to EAI and education, adolescence, orphans, high social status, and alcohol consumption of parents is given in Table 2. The mean age of EAI children was $16.2 \pm 1.3$ years (range: 13 - 18 years) vs $11.4 \pm 3.5$ years (range: $5-18$ years) for others $(\mathrm{p}<$ 0.001 ). The average sibling of EAI children was $4.3 \pm 2.2$ (range: $1-10$ ) vs $3.3 \pm$ 1.8 (range: 1 - 12) for others $(\mathrm{p}<0.0001)$. Independent determinants of EAI in logistic regression are noted in Table 3. The ROC of relationship between age and EAI has objectified an AUC of 0.891 (95\% CI: $0.86-0.92 ; \mathrm{p}<0.001)$ with a sensitivity of $74.1 \%$ and a specificity of $85.1 \%$ for 15.5 years old (Figure 2 ).

\subsection{Cigarette Smoking}

Fifteen students (2.5\%, 95\% CI: 1.5 - 4.2) admitted to being active smokers. The distribution of smokers children by school level, adolescence, high social status, parental smoking and orphans is reported in Table 2. The mean age of smokers

Cigarette smoking

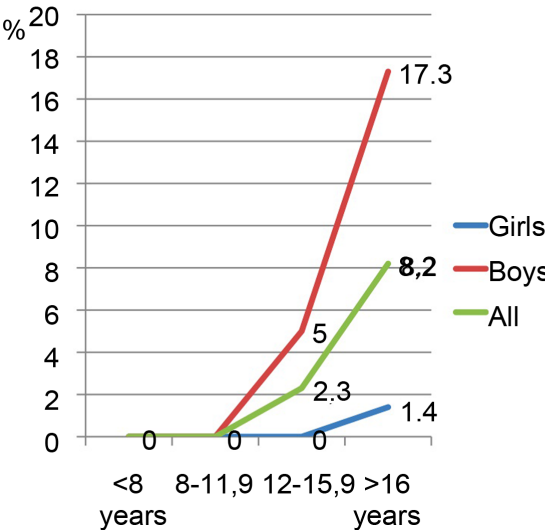

(a)
Excessive alcohol intake

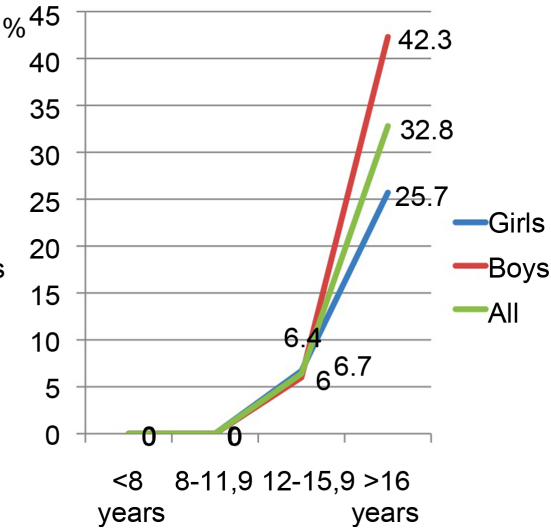

(b)

Figure 1. Evolution of prevalence of cigarette smoking (a) and excessive alcohol intake (b) by age range and sex.

Table 2. Distribution of students according to addiction, type of schooling, adolescence and orphan status.

\begin{tabular}{ccccccc}
\hline & \multicolumn{3}{c}{ Alcohol intake } & \multicolumn{2}{c}{ Cigarette smoking } \\
\cline { 2 - 7 } & yes & no & yes & no \\
\cline { 2 - 7 } & (n=54) & $(\mathrm{n}=549)$ & p-value & $(\mathrm{n}=15)$ & $(\mathrm{n}=588)$ & p-value \\
\hline High school & $49(90.7)$ & $239(43.5)$ & $<0.001$ & $11(73.3)$ & $277(47.1)$ & $<0.05$ \\
Public school & $31(57.4)$ & $253(46)$ & NS $^{*}$ & $11(73.3)$ & $277(47.1)$ & $<0 ; 05$ \\
Adolescents & $52(96.3)$ & $256(46.6)$ & $<0.001$ & $15(100)$ & $293(49.8)$ & $<0.001$ \\
Orphans & $13(24.1)$ & $25(4.6)$ & $<0.001$ & $5(33.3)$ & $33(5.6)$ & $<0.001$ \\
HSL & $27(50)$ & $333(60.9)$ & NS* & $4(26.7)$ & $356(60.5)$ & $<0.001$ \\
Alcoholism in parent & $41(76)$ & $278(50.6)$ & $<0.001$ & - & - & - \\
Smoking in parent & - & - & - & $4(26.6)$ & $60(10.2)$ & NS $^{*}$
\end{tabular}

${ }^{\star}$ NS: no significant; ${ }^{*}$ HSL: High social level. 
Table 3. Independants determinants of alcoholism and cigarette smoking in logistic regression analysis.

\begin{tabular}{cccccc}
\hline & $\beta$ coefficient & Standard error & Wald $\chi^{2}$ & OR (95\% CI) & p-value \\
\hline ALCOHOL INTAKE & & & & & \\
\hline Age (years) & 0.708 & 0.146 & 4.851 & $2(1.5-2.7)$ & $<0.0001$ \\
Alcoholism in parents (yes/no) & 1.166 & 0.411 & 2.833 & $3.2(1.43-7.1)$ & 0.004 \\
Orphans (yes/no) & 1.156 & 0.467 & 2.473 & $3.2(1.2-8)$ & 0.01 \\
Siblings & -0.504 & 0.162 & -3.105 & $0.6(0.4-0.83)$ & 0.002 \\
HSL* (yes/no) & -0.77 & 0.303 & -2.55 & $0.45(0.25-0.8)$ & 0.01 \\
\hline CIGARETTE SMOKING & & & & & \\
\hline Siblings & 0.303 & 0.151 & 1.998 & $1.3(1.0-1.8)$ & 0.04 \\
Migration (yes or no) & 2.483 & 0.854 & 2.904 & $12(2.2-63)$ & 0.003 \\
Orphans (yes or no) & 3.674 & 1.153 & 3.186 & $39(4-378)$ & 0.001 \\
Sex (male vs female) & 2.401 & 0.538 & 4.459 & $11(3.8-31)$ & $<0.0001$ \\
\hline
\end{tabular}

HSL: High social level.

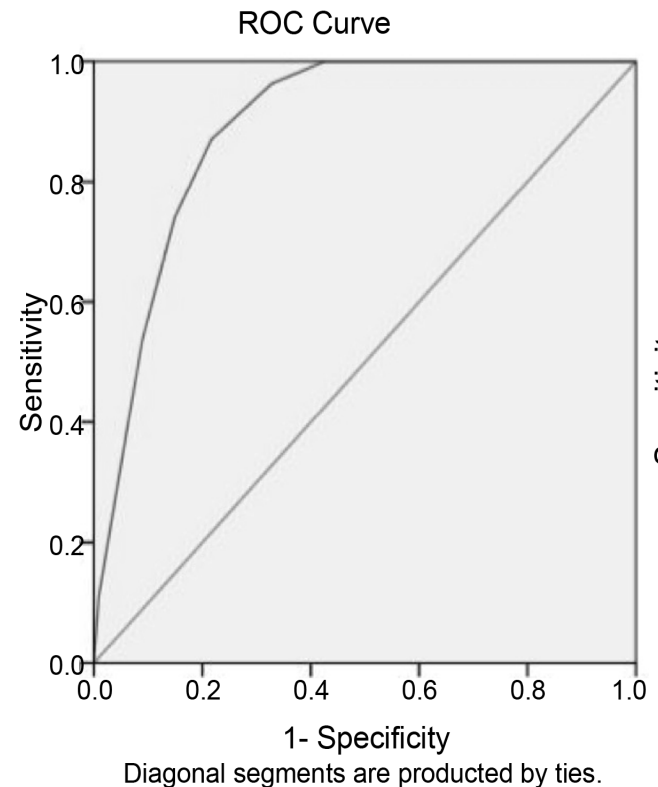

(a)

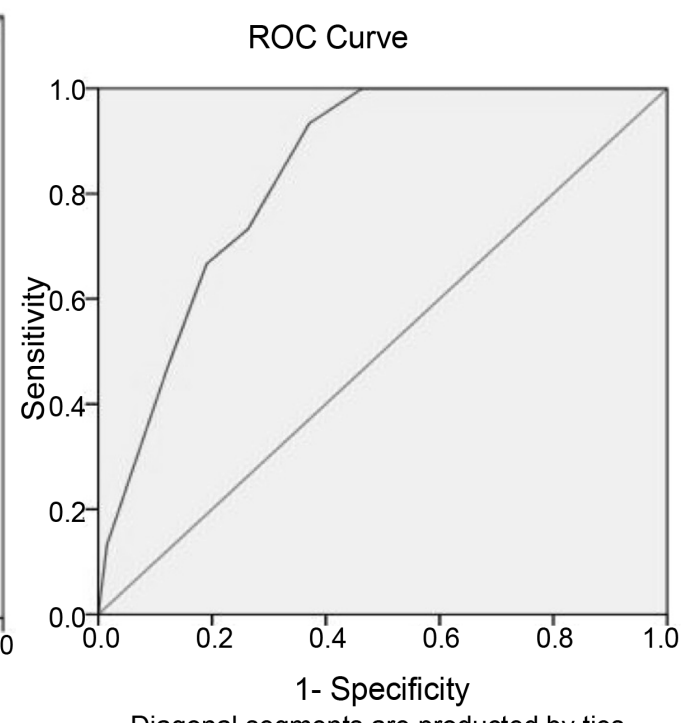

Diagonal segments are producted by ties.

(b)

Figure 2. (a) ROC of relationship of age with excessive alcohol intake, AUC $=0.891$ (95\% CI: 0.86 $0.92, \mathrm{p}<0.001$ ), and age of 15.5 years had a sensitivity of $74.1 \%$ and specificity of $85.1 \%$. (b) ROC of relationship of age and cigarette smoking: $\mathrm{AUC}=0.839(95 \% \mathrm{CI}: 0.77-0.90, \mathrm{p}=0.035)$ and age of 14.5 years was determine cigarette smoking in sensitivity of $73.3 \%$ and specificity of $73.6 \%$.

was $15.9 \pm 1.5$ years (range: 13 - 18 years) vs $11.7 \pm 3.6$ years (range: 5 - 18 years) for others $(\mathrm{p}=0.005)$. The evolution of prevalence of CS by age range is given in Figure 1(b). The average siblings of smoking was $5.6 \pm 2.5$ (range: 3 - 10) vs $3.4 \pm$ 1.8 (range: 1 - 12) in no-smokers $(\mathrm{p}=0.08)$. Independent determinants of CS are shown in Table 3. The ROC analysis of the relationship between age and CS showed a sensitivity of $73.3 \%$ and a specificity of $73.6 \%$ (AUC $=0.839,95 \%$ CI: $0.77-0.90, \mathrm{p}=0.035$ ) for 14.5 years old (Figure $2(\mathrm{~b})$ ). 


\section{Discussion}

\subsection{Limitation of Methodology}

This study was conducted in school facilities in the capital of Congo. Thus, the prevalence of addiction is not about the school environment or the reality of the other cities. We did not investigate the link between addiction and medical history, or biological variables. Intoxication addiction has not been identified in all (dosage, quality, quantity and type of alcohol consumed, quality of tobacco). Similarly, some social aspects such as the environment, the context of social conflict and the influence of associates have been addressed. Some aspects to parents such as domestic violence or the return of a conflict zone have not been considered. Nevertheless, this is the first study that assesses smoking in schools of Brazzaville.

\subsection{Excessive Alcohol Intake}

Its prevalence in schools is $9 \%$. But its consumption is more evident among older students ( 16.2 years): $32.8 \%$ of boys and $25.7 \%$ girls. The independent determinants of alcoholism in our series are: age, addiction in parents, large families and low socio-economic level. Mabiala et al. [5] had reported a prevalence of $22.8 \%$ among adolescents in urban areas, among them $19.3 \%$ were enrolled. This author had linked alcoholism to age, but also death, divorce and parental alcoholism [5]. In sub-Saharan Africa, it is mostly teenagers who are affected. In Zambia, Swhan et al. describes a major impact of advertising on alcohol consumption among students, and the prevalence was $42.6 \%$ [4]. In Gabon, Mimbila-Mayi et al. reported a prevalence of $55.5 \%$ among adolescents [7]. In rural South Africa, the prevalence of alcoholism is $22 \%$ among school adolescents [12]. In this country, consumption mainly concerns the high teens, male, school late, but there is no impact of social status [13]. Also, parental influence is revealed as an important determinant [14]. Alcohol is also implicated in the occurrence of suicidal ideation in adolescents [2]. For Karibu et al., religion is revealed an important factor against alcoholism among adolescents [8].

\subsection{Cigarette Smoking}

Its prevalence was $2.5 \%$, but $8.2 \%$ among schoolchildren over 16 years old. This is from 12 years schoolchildren smoke in our series. Girls smoke very little (0.3\%). Indeed, sub-Saharan Africa, tobacco use among girls is interpreted as a sign of lightness and molestation [8]. The law against tobacco adopted in Congo prohibits the sale of tobacco near schools [10]. Moreover, this law prohibits advertising and promotion of tobacco by the media. However, the prevalence of CS of our study is comparable to $5.1 \%$ gain in Tanzania [2]. In contrast, the rate of smoking among adolescents is higher in other African countries: $15.5 \%$ in Tanzania [9], 21.5\% in Gabon [7] and 39.1\% in South Africa [6]. It should be noted that the prevalence of smoking are much higher outside Africa $47.5 \%$ in Chile and $44.7 \%$ in the USA [2]. Factors associated with smoking in our series were: age, large family, migration, orphans and male sex and low social status. In his 
series, Madu et al. had as other factors associated with smoking: stress, fatigue and parties [6]. Mexico Reddy Jacobs et al. had the link between low social status and tobacco consumption [3].

\subsection{Outlook}

The influence of age in addiction seems attached to the sense of independence of adolescents, but also the impact of the environment, particularly advertising [4] [12]. The influence of the use of these substances among parents is also a key element, as well as deleterious social environment. In Congo, although tobacco advertising is prohibited, internet and foreign channels still allow this promotion. In view of acute and chronic consequences of alcoholism and smoking, including cardiovascular disease, prevention seems an inexpensive way to fight in our country. This primary prevention targeting children in schools should be integrated into school curricula and should be done early [15]. It was noted that children whose process of consumption of these substances is likely to emerge, the intervention must be early [15]. Indeed, once the addiction developed neuroanatomical and pharmacological changes will the various interventions to be uncertain and often contain no improvement [14].

\section{Conclusion}

Smoking and alcoholism addictions among schoolchildren in Brazzaville concern mainly male adolescents. The use of alcohol is greater than that of the tobacco. This fact marks the change of manners, and exposes these students to acute complications and later chronicles. Prevention should be done early, targeting the associated factors.

\section{Acknowledgements}

The authors thank M. Ngakala Ignace, CEO of University Hospital of Brazzaville and Mrs. Opimbat-Mboundza Charlotte for their logistical support. The team of investigators on the grounds included: Dr Sah Mbou Bertrand, Dr Esther Ngoyi Ontsira, Dr Elion-Ossibi Pierlesky, Dr Togho Lande, Dr Pierre Poaty, Dr Kevin Bouhelo-Pam, Miss Okiemy Cardinale, M. Fabrice Nkoua, M. Ngouma Amour, M. Nguenguie Kessara and Dr Atipo-Tsiba PW.

\section{References}

[1] Brook, D.W., Rubenstone, E., Zhang, C., Morojele, N.K. and Brook, J.S. (2011) Environmental Stressors, Low Well-Being, Smoking, and Alcohol Use among South African Adolescents. Social Science \& Medicine, 72, 1447-1453. https://doi.org/10.1016/j.socscimed.2011.02.041

[2] Innamorati, M., De Leo, D., Rihner, Z., Serafini, G., Brugnoli, R., Lester, D., Amore, M., Pompili, M. and Girardi, P. (2011) Tobacco Smoking and Suicidal Ideation in School-Aged Children 12-15 Years Old: Impact of Cultural Differences. Journal of Addictive Diseases, 30, 359-367. https://doi.org/10.1080/10550887.2011.609802

[3] Reddy-Jacobs, C., Téllez-Rojo, M.M., Meneses-Gonzalez, F., Campuzan-Rincon, J. and Hernandez-Avila, M. (2006) Poverty, Youth and Consumption of Tobacco in 
Mexico. Salud Pública de México, 48, S83-S90.

[4] Swahn, M.H., Ali, B., Palmier, J.B., Sikazwe, G. and Mayeya, J. (2011) Alcohol Marketing, Drunkenness, and Problem Drinking among Zambian Youth: Findings from the 2004 Global School-Based Student Health Survey. Journal of Environmental and Public Health, Article ID: 497827.

[5] Mabiala-Babela, J.R., Mahoungou-Guimbi, K.C., Massamba, A. and Senga, P. (2005) Alcohol Consumption among Teenagers in Brazzaville (Congo). Santé, 15, 153-160.

[6] Madu, S.N. and Matla, M.Q. (2003) Illicit Drug Use, Cigarette Smoking, Alcohol Drinking Behaviour Smong a Sample of High School Adolescents in the Pietersburg Area of the Nothern Province, South Africa. Journal of Adolescence, 26, 121-136. https://doi.org/10.1016/S0140-1971(02)00120-3

[7] Mimbila-Mayi, M., Nzame Vierin, Y., Biloghe, A. and Moussavou-Mouyama, A. (2010) Consumption of Addictive Substances by Gabonese Teenagers: An Epidemiological Survey. Santé, 21, 149-152.

[8] Kabiru, C., Beguy, D., Crichton, J. and Ezeh, A.C. (2010) Self-Reported Drunkenness among Adolescents in Four Sub-Saharan African Countries: Associations with Adverse Childhood Expériences. Child and Adolescent Psychiatry and Mental Health, 4, 17. https://doi.org/10.1186/1753-2000-4-17

[9] Mnyika, K.S., Masatu, M.C. and Klepp, K.I. (2011) Prevalence of and Predictors of Substance Use among Adolescents in Rural Villages of Moshi District, Tanzania. East African Journal of Public Health, 8, 1-5.

[10] Loi No. 12-2012 relative à la lutte anti-tabac. Journal Officiel de la République du Congo, 54, 567-568. www.sgg.cg/imageProvider.asp?private_resource $=1610 \& \mathrm{fn}=\mathrm{jo} \_2012 \_28 . p d f$

[11] Kimbally-Kaky, G., Gombet, T., Voumbo, Y., et al. (2008) Rheumatic Heart Disease in School Children in Brazzaville. Medicine Tropicale, 68, 603-605.

[12] Onya, H., Tessera, A., Myers, B. and Flisher, A. (2012) Adolescent Alcohol Use in Rural South African High Schools. African Journal of Psychiatry, 15, 352-357. https://doi.org/10.4314/ajpsy.v15i5.44

[13] Ramsoomar, L., Morojele, N.K. and Norris, S.A. (2013) Alcohol Use in Early and Late Adolescence among the Birth to Twenty Cohort in Soweto, South Africa. Global Health Action, 6, 19274. https://doi.org/10.3402/gha.v6i0.19274

[14] Hoque, M. and Ghuman, S. (2012) Do Parents Still Matter Regarding Adolescents' Alcohol Drinking? Experience from South Africa. International Journal of Environmental Research and Public Health, 9, 110-122. https://doi.org/10.3390/ijerph9010110

[15] Stanis, J.J. and Andersen, S.L. (2004) Reducing Substance Use during Adolescence: A Translational Framework for Prevention. Psychopharmacology, 231, 1437-1453. https://doi.org/10.1007/s00213-013-3393-1 
Submit or recommend next manuscript to SCIRP and we will provide best service for you:

Accepting pre-submission inquiries through Email, Facebook, LinkedIn, Twitter, etc. A wide selection of journals (inclusive of 9 subjects, more than 200 journals)

Providing 24-hour high-quality service

User-friendly online submission system

Fair and swift peer-review system

Efficient typesetting and proofreading procedure

Display of the result of downloads and visits, as well as the number of cited articles Maximum dissemination of your research work

Submit your manuscript at: http://papersubmission.scirp.org/

Or contact ojped@scirp.org 